\title{
Substituição do Milho por Farelo de Palma Forrageira em Dietas para Ovinos em Crescimento. Consumo e Digestibilidade ${ }^{1}$
}

\author{
Robson Magno Liberal Véras ${ }^{2}$, Marcelo de Andrade Ferreira ${ }^{3,5}$, Antonia Sherlânea Chaves Véras ${ }^{3,5}$, \\ Francisco Fernando Ramos de Carvalho ${ }^{3}$, Carmen Valéria de Araújo Cavalcanti ${ }^{4}$, Gladston Rafael \\ Arruda Santos ${ }^{4}$, Sandro de Souza Mendonça ${ }^{6}$, Carla Aparecida Soares ${ }^{7}$, Cláudia Batista Sampaio ${ }^{8}$
}

\begin{abstract}
RESUMO - A digestibilidade aparente e os consumos de matéria seca (MS), de matéria orgânica (MO), de proteína bruta (PB), de fibra em detergente neutro (FDN) e de nutrientes digestíveis totais (NDT) foram avaliados para se determinar o efeito da substituição do milho por farelo de palma forrageira (0,33, 66 e 100\%), em dietas de ovinos em crescimento. Objetivou-se, também, a comparação da estimativa de digestibilidade aparente por intermédio dos métodos de coleta total de fezes e de indicadores internos (fibra em detergente ácido [FDAi] e fibra em detergente neutro [FDNi] indigestíveis). Foi empregado delineamento experimental em quadrado latino, constituído de quatro animais, quatro períodos e quatro níveis de substituição do milho por farelo de palma forrageira. Não houve efeito da substituição sobre os consumos de MS, MO, PB e FDN. O consumo de NDT diminuiu linearmente com a inclusão de farelo de palma nas dietas. Os coeficientes de digestibilidade aparente da MS e MO diminuíram linearmente, enquanto os de PB e FDN não foram influenciados pela substituição. Não houve diferença entre a coleta total de fezes e o indicador interno FDNi na estimativa da digestibilidade dos nutrientes.
\end{abstract}

Palavras-chave: alimento alternativo, carboidratos, energia, indicador interno

\section{Replacement of Corn by Forage Cactus Meal in Growing Lambs Diets. Intake and Digestibility}

\begin{abstract}
The apparent digestibility and the intakes of dry matter (DM), organic matter (OM), crude protein (CP), neutral detergent fiber (NDF) and total digestible nutrients (TDN) were estimated to evaluate the effects of replacement by corn by forage cactus meal $(0,33,66$ and $100 \%)$ in growing lambs diets. It was also aimed to compare the internal markers, indigestible neutral detergent (NFDi) and acid detergent fiber (ADFi) with total feces collection to estimate the apparent digestibility of nutrients. A 4 x 4 latin square experimental design with four lambs, four periods and four levels of replacement of corn by forage cactus meal, was used. The replacement of corn by forage cactus meal did not affect the intakes of DM, OM, CP and NDF. TDN intake decreased linearly. The apparent digestibility of DM and OM decreased linearly, but no effect was observed for CP and NDF digestibilities. There was no difference between NDFi and total feces collection in the estimate of nutrients digestibility.
\end{abstract}

Key Words: alternative food, carbohydrates, energy, internal marker

\section{Introdução}

A produção de ruminantes no Brasil baseia-se na utilização de pastagens naturais ou cultivadas. Por outro lado, é bastante conhecida a descontinuidade de produção de forragem durante o ano, ocorrendo um período de abundância de forragem com valor nutritivo relativamente alto, em contraposição a um período de escassez de alimentos com baixo valor nutritivo.

A busca por melhores resultados na pecuária é alcançada com o uso de concentrados, principalmente nas épocas críticas, considerando tanto o volume como a qualidade deste suplemento. O milho é a principal fonte de energia utilizada no Brasil para compor os concentrados, porém sofre grande variação de preço ao longo do ano, haja vista sua intensa utilização na alimentação humana e na dieta de aves e suínos. Em decorrência disso, vários trabalhos têm sido desenvolvidos no intuito de encontrar fontes de energia alternativas ao milho na dieta de ruminantes.

Geron et al. (2001) avaliaram o efeito da substituição do milho pela farinha de varredura de mandioca

\footnotetext{
1 Trabalho parcialmente financiado pela FACEPE, parte da dissertação do primeiro autor apresentada ao Programa de Pós-Graduação em Zootecnia da UFRPE

2 Aluno do Programa de Pós-Graduação em Zootecnia da UFV (rmlv2002@yahoo.com.br).

3 Professores do Depto de Zootecnia - UFRPE (ferreira@ufrpe.br).

${ }^{4}$ Alunos do Programa de Pós-Graduação em Zootecnia da UFRPE.

5 Bolsista do CNPq.

6 Professor do DTRA/UESB (sandrosmendonca@yahoo.com.br).

7 Mestre em Zootecnia/UFV.

8 Aluna do curso de Graduação em Zootecnia, DZO - UFV.
} 
(25;50;75e 100\%) sobre a ingestão voluntária de matéria seca e valor energético, na dieta de ovinos. Não foi encontrado efeito na ingestão de matéria seca e digestibilidade da energia bruta das rações com os níveis de substituição adotados, indicando que a farinha de varredura poderia substituir o milho nas rações de ovinos.

Mouro et al. (2001) e Branco et al. (2001) substituindo o milho pela farinha de varredura de mandioca, em dietas de cabras em lactação, não verificaram diferença na ingestão e digestibilidade aparente de matéria seca (MS), matéria orgânica (MO), proteína bruta (PB), fibra em detergente neutro (FDN), carboidratos não-fibrosos (CNF) e extrato etéreo (EE), bem como no teor dos nutrientes digestíveis totais (NDT) das dietas, porém houve aumento linear na digestibilidade aparente do amido, com a inclusão da farinha de varredura.

Véras et al. (2002) ao trabalharem com 0; 25; 50 e $75 \%$ de substituição do milho moído pelo farelo de palma, em ensaio de digestibilidade com ovinos, não encontraram diferenças significativas para o consumoe a digestibilidade de MS, MO, PB, EE, FDNe carboidratos totais (CHOT) e o teor de NDT. Contudo, Menezes et al. (2002), avaliando a substituição do milho pela casca de mandioca em rações para caprinos, observaram efeito linear decrescente, em função dos níveis de substituição, para os coeficientes de digestibilidade de MS, MO, PB, FDN, FDA e energia bruta (EB).

Garcia \& Silva Sobrinho (1998), trabalhando com a substituição do milho pelo resíduo de panificação "biscoito", em diferentes níveis $(0 ; 33 ; 66$ e $100 \%$ ) na dieta de cordeiros, verificaram que, com o aumento dos níveis de substituição, houve redução no ganho de peso, na ingestão de MS, na digestibilidade da PB e na conversão alimentar.

A digestibilidade do alimento representa a capacidade do animal em utilizar seus nutrientes, em maior ou menor escala, expressa pelo coeficiente de digestibilidade do nutriente em apreço, sendo uma característica do alimento, e não do animal (Coelho da Silva \& Leão, 1979).

Na determinação da digestibilidade, Berchielli et al. (2000) comentaram a importância do uso de métodos indiretos (indicadores ou marcadores), que apresentam certas vantagens sobre a coleta total de fezes, a exemplo da simplicidade e conveniência de utilização, além de proporcionar uma série de informações, como a quantidade ingerida de alimentos ou nutrientes específicos, a taxa de passagem da digesta por todo o trato digestivo e a digestibilidade de todo alimento ou nutrientes específicos.
Alves et al. (2003), trabalhando com ovinos em crescimento, compararam a estimativa da produção de matéria seca fecal, utilizando a fibra em detergente ácido indigestível (FDAi) como indicador interno e o método de coleta total, e verificaram que não houve diferença entre os métodos para a digestibilidade dos nutrientes. Esses autores concluíram que a FDAi pode ser utilizada como indicador interno para estimativa do coeficiente de digestibilidade em ovinos. Porém, Zeoula et al. (2001) encontraram resultados diferentes, mostrando que a cinza insolúvel em ácido (CIA) e fibra em detergente neutro indigestível (FDNi) foram indicadores adequados em estimar a digestibilidade da MS, quando comparados com o método de coleta total de fezes.

Objetivou-se, nesta pesquisa, avaliar efeito da substituição do milho moído pelo farelo de palma ( 0 ; 33; 67 e 100\%) sobre o consumo e a digestibilidade aparente de MS, MO, PB, EE e FDN e o teor de NDT e comparar métodos (coleta total de fezes e indicadores internos FDAi e FDNi) para estimativa da digestibilidade aparente das dietas experimentais.

\section{Material e Métodos}

O trabalho foi conduzido no galpão de desempenho e digestibilidade do setor de caprino-ovinocultura do Departamento de Zootecnia da Universidade Federal Rural de Pernambuco - UFRPE.

Quatro ovinos sem raça definida (SRD) machos não-castrados, em crescimento (idade média de 6 meses e peso vivo médio de $20 \mathrm{~kg}$ ), foram distribuídos em delineamento quadrado latino 4 x 4, com quatro tratamentos $(0 ; 33 ; 66$ e 100\% de substituição do milho pelo farelo de palma) e quatro períodos. As dietas foram formuladas para atender às exigências de ganho de peso de $200 \mathrm{~g}$, segundo o NRC (1985).

Os animais foram mantidos em gaiolas individuais de ensaios metabólicos (1,1 m x 0,55 m), dotadas de comedouro, bebedouro e cocho de sal, além de coletores de fezes e urina. A relação volumoso:concentrado foi de 50:50. O volumoso utilizado foi o feno de Tifton-85 (Cynodon dactylon), que foi moído em máquina forrageira com peneira de crivo de $8 \mathrm{~mm}$ e colocado em sacos de náilon, para facilitar o armazenamento. $O$ farelo de palma, cultivar Gigante (Opuntia fícus indica Mill), foi fornecido pela Estação Experimental de Serra Talhada - PE, pertencente à Empresa Pernambucana de Pesquisa Agropecuária - IPA, onde a palma foi picada, seca ao sol por três dias e moída para obtenção do farelo. A 
composição dos ingredientes das dietas experimentais encontra-se na Tabela 1 e dos alimentos, na Tabela 2.

Inicialmente, os animais foram pesados, identificados e tratados contra ecto e endoparasitas. Em seguida, passaram por um período de adaptação às instalações e manejo de 30 dias, quando foi estimado o consumo voluntário, fazendo-se ajustes diários da quantidade oferecida. O ensaio de digestibilidade teve duração de 48 dias, sete para adaptação dos animais às dietas de cada período experimental e cinco para coleta, totalizando quatro períodos de coletas. Consta na Tabela 3 a composição bromatológica das dietas experimentais.

Os alimentos foram fornecidos duas vezes ao dia, na forma de ração completa, com água à disposição dos animais. Durante os cinco dias de coleta a quantidade de ração oferecida, bem como as sobras foram pesadas diariamente, amostradas (10\%), identificadas e guardadas em freezer. As fezes excretadas durante este período também foram pesadas e amostradas (10\%), sendo, em seguida identificada e armazenada a $-15^{\circ} \mathrm{C}$. Ao final do experimento, as amostras foram descongeladas à temperatura ambiente. Posteriormente, todas as amostras de cada tratamento foram pré-secas em estufa com circulação forçada a $65^{\circ} \mathrm{C}$, por 72 horas, e misturadas, para constituir uma amostra composta (homogeneizada e, após, retirada uma alíquota de aproximadamente $10 \%$, moída em peneira com crivo de $1 \mathrm{~mm}$ ) para posteriores análises laboratoriais.

Tabela 1 - Composição percentual dos ingredientes nas dietas (\% na MS)

Table 1 - Percentage of the ingredient in the diets (\% of DM)

\begin{tabular}{lcccc}
\hline $\begin{array}{l}\text { Ingredientes } \\
\text { Ingredients }\end{array}$ & \multicolumn{4}{c}{$\begin{array}{c}\text { Níveis de substituição (\%) } \\
\text { Levels of replacement (\%) }\end{array}$} \\
\cline { 2 - 5 } & 0 & 33 & 66 & 100 \\
\hline $\begin{array}{l}\text { Feno de Tifton } \\
\begin{array}{l}\text { Tifton hay } \\
\text { Milho }\end{array}\end{array}$ & 49,2 & 50,0 & 50,0 & 50,2 \\
$\begin{array}{l}\text { Corn } \\
\text { Farelo de palma }\end{array}$ & 28,3 & 18,8 & 9,4 & 0,0 \\
$\begin{array}{l}\text { Forage cactus meal } \\
\text { Farelo de soja }\end{array}$ & 0,0 & 9,4 & 18,9 & 28,3 \\
$\begin{array}{l}\text { Soybean meal } \\
\text { Calcário }\end{array}$ & 21,5 & 21,5 & 21,5 & 21,5 \\
$\begin{array}{l}\text { Limestone } \\
\text { Total }\end{array}$ & 1,0 & 0,3 & 0,0 & 0,0 \\
Total & 100 & 100 & 100 & 100 \\
\hline
\end{tabular}

Suplemento mineral (mineral suplementt): $\mathrm{Ca}-140,0 \mathrm{~g}$; P-65,0 g; S-15,0 g; Mg- 15,0 g; Zn- 3.500,0 mg; Mn-3.000,0; I-60,0 mg; Se10,0 mg; Co-100,0 mg; Vit A-50.000,0 Ul/kg; Fluor(máx)- 650,0 mg.
As determinações de MS, matéria mineral (MM), PB, EE e FDA foram realizadas conforme Silva (1990) e as de FDN, de acordo com Van Soest et al. (1991).

A determinação da digestibilidade por meio dos indicadores (FDAi e FDNi) foi feita segundo metodologia descrita por Berchielli et al. (2000). Assim, amostras de alimentos, sobras e fezes foram incubadas no rúmen de um bovino adulto, mestiço, castrado, por 144 horas, em sacos tipo ANKOM. A quantidade de amostra incubada foi de $1,0 \mathrm{~g}$ para alimentos concentrados e $0,5 \mathrm{~g}$ para feno, fezes e sobras. O material remanescente da incubação foi submetido à lavagem com detergentes neutro e ácido, sendo os resultados considerados FDNi e FDAi, respectivamente. Para determinação da produção de matéria seca fecal (PMSF), com o uso de indicador interno, foi utilizada a seguinte equação:

PMSF = indicador consumido/concentração de indicador nas fezes

Ocoeficiente dedigestibilidade(CD) foi calculadopor:

$$
\mathrm{CD}=\frac{(\text { Nutriente ingerido }- \text { Nutriente excretado })}{\text { Nutriente ingerido }} \times 100
$$

O consumo de nutrientes digestíveis totais (NDT) foi calculado por:

Consumo de NDT $=(\mathrm{PB}$ ingerido - PBfecal $)+$ 2,25(EE ingerido - EEfecal $)+($ CHOT ingerido. CHOT fecal) (Sniffen et al., 1992)

em que $\mathrm{CHOT}=100-(\mathrm{PB}+\mathrm{EE}+\mathrm{MM})($ Sniffen et al., 1992).

A concentração de NDT foi calculada por:

$\%$ de NDT $=$ Consumo de NDT/Consumo de MS (Sniffen et al., 1992).

Os dados de consumo e digestibilidade foram submetidos a análises de variância e de regressão, em função dos níveis de substituição do milho pelo farelo de palma, por intermédio do SAEG - Sistemas de Análises Estatísticas e Genéticas (UFV, 1997).

Para comparação entre os métodos de determinação da digestibilidade, foi utilizado o esquema de parcelas subdivididas, em que os tratamentos consti- 
Tabela 2 - Composição química dos alimentos (\% MS)

Table 2 - Chemical composition of the feedstuffs (\% DM)

\begin{tabular}{|c|c|c|c|c|c|}
\hline \multirow[b]{2}{*}{ Itens (Items) } & \multicolumn{4}{|c|}{ Ingredientes (Feedstuffs) } & \multirow[b]{2}{*}{$\begin{array}{l}\text { Calcário } \\
\text { Limestone }\end{array}$} \\
\hline & $\begin{array}{l}\text { Milho } \\
\text { Corn }\end{array}$ & $\begin{array}{l}\text { Farelo de palma } \\
\text { Forage cactus meal }\end{array}$ & $\begin{array}{l}\text { Farelo de soja } \\
\text { Soybean meal }\end{array}$ & $\begin{array}{c}\text { Feno de Tifton } \\
\text { Tifton hay }\end{array}$ & \\
\hline $\operatorname{MS}(\%)(D M \%)$ & 86,05 & 90,00 & 88,72 & 87,57 & 99 \\
\hline $\mathrm{MO}^{1}(O M)$ & 97,12 & 98,89 & 93,12 & 93,14 & - \\
\hline $\mathrm{EE}^{1}(E E)$ & 3,54 & 1,69 & 1,84 & 1,76 & - \\
\hline $\mathrm{PB}^{1}(C P)$ & 8,50 & 6,95 & 48,67 & 8,00 & - \\
\hline $\mathrm{FDN}^{1}(N D F)$ & 15,28 & 29,95 & 19,00 & 72,42 & - \\
\hline $\mathrm{FDA}^{1}(A D F)$ & 3,60 & 15,00 & 12,00 & 42,80 & - \\
\hline $\mathrm{Ca}^{1}$ & 0,17 & 20,70 & 2,60 & 3,70 & 360 \\
\hline $\mathrm{P}^{1}$ & 2,60 & 1,80 & 6,30 & 1,57 & - \\
\hline
\end{tabular}

$1 \%$ na matéria seca ( $\%$ of $D M)$

Tabela 3 - Teores de matéria seca (MS), matéria orgânica (MO), proteína bruta (PB), extrato etéreo (EE), fibra em detergente neutro (FDN), fibra em detergente ácido (FDA), carboidratos totais (CHOT) e nutrientes digestíveis totais (NDT) das rações experimentais

Table 3 - Contents of dry matter (DM), organic matter (OM), crude protein $(C P)$, ether extract $(E E)$, neutral detergent fiber(NDF), acid detergent fiber (ADF), total carbohydrates (TC) and total digestible nutrients (TDN) of the diets

\begin{tabular}{lcccr}
\hline $\begin{array}{l}\text { Nutrientes } \\
\text { Nutrient }\end{array}$ & \multicolumn{4}{c}{$\begin{array}{c}\text { Níveis de substituição(\%) } \\
\text { Levels of replacement }(\%)\end{array}$} \\
\cline { 2 - 5 } & 0 & 33 & 66 & 100 \\
\hline $\mathrm{MS}^{\prime}(D M \%)$ & 86,92 & 87,32 & 87,12 & 87,28 \\
$\mathrm{MO}^{1}\left(O M^{1}\right)$ & 93,83 & 92,26 & 91,03 & 89,32 \\
$\mathrm{~PB}^{1}\left(C P^{1}\right)$ & 18,40 & 18,18 & 17,77 & 17,51 \\
$\mathrm{EE}^{1}\left(E E^{1}\right)$ & 1,09 & 1,37 & 1,34 & 1,34 \\
$\mathrm{FDN}^{1}\left(N D F^{1}\right)$ & 52,78 & 55,11 & 56,57 & 58,70 \\
$\mathrm{FDA}^{1}\left(A D F^{1}\right)$ & 25,12 & 27,39 & 29,13 & 30,88 \\
$\mathrm{CHOT}^{1}\left(T C^{1}\right)$ & 74,34 & 72,74 & 71,91 & 70,46 \\
NDT $\left.^{\prime} \%\right)(T D N)$ & 62,88 & 60,53 & 54,78 & 51,35 \\
\hline
\end{tabular}

$1 \%$ na matéria seca (\% DM).

tuíram a parcela, e os métodos, as subparcelas, com posterior análise de variância e comparação de médias pelo teste de Tukey, a 5\% de probabilidade.

\section{Resultados e Discussão}

Constam na Tabela 4 as médias, as equações de regressão e os coeficientes de determinação e de variação, relativos ao consumo de nutrientes.

Os consumos de MS, MO, FDN e PB não foram influenciados pela substituição do milho pelo farelo de palma forrageira, o que se deve, em parte, à concentração destes nutrientes, com exceção da FDN, nas dietas experimentais (Tabela 3). Resultados semelhantes foram verificados por Véras et al. (2002), ao fornecerem farelo de palma em substituição ao milho na dieta de carneiros sem raça definida (SRD). Segundo esses autores, a palma forrageira apresenta alta palatabilidade, com grande aceitação pelos animais. Outro fator importante é que a palma, diferentemente de outras forragens, apresenta alta taxa de digestão ruminal, sendo a matéria seca degradada extensa e rapidamente, favorecendo maior taxa de passagem e, conseqüentemente, consumo semelhante ao dos concentrados (Silva et al., 1997).

O consumo de NDT diminuiu linearmente $(\mathrm{P}<0,05)$ com a inclusão do farelo de palma. Este comportamento pode ser explicado pela ausência de efeito no consumo de MS e pelo teor de NDT das dietas experimentais (Tabela 3 ), que está diretamente relacionado ao menor teor energético da palma, se comparado com o milho.

Constam na Tabela 5 as médias, as equações de regressão e os coeficientes de determinação e de variação para os coeficientes de digestibilidade aparente de diferentes nutrientes, além do teor de NDT das dietas experimentais.

Os coeficientes de digestibilidade aparente da matéria seca e matéria orgânica e os teores de NDT das dietas decresceram linearmente $(\mathrm{P}<0,05)$ com a inclusão do farelo de palma. Este comportamento ocorreu, provavelmente, em razão da maior concentração de carboidratos não-fibrosos presentes no milho $(72,1 \%$, Zeoula et al., 2001), enquanto a palma forrageira apresenta em torno de 60\% (Wanderley et al., 2002). Observou-se aumento nos teores de FDA nas dietas experimentais, comainclusãodofarelode palma(Tabela3).

Os coeficientes de digestibilidade aparente da FDN e PB não foram influenciados pela inclusão do farelo de palma, apesar da redução de $14 \%$ entre os níveis 0 e $100 \%$ de substituição, com relação ao 
Tabela 4 - Média, equação de regressão ajustada (ER), coeficiente de determinação ( $\left.r^{2}\right)$ e variação (CV) de consumo de matéria seca (CMS), matéria orgânica (CMO), fibra em detergente neutro (CFDN), proteína bruta (CPB) e nutrientes digestíveis totais (CNDT), em função dos níveis de substituição do milho pelo farelo de palma

Table 4 - Mean, fitted regression equation (RE), coefficients of determination $\left(r^{2}\right)$ and variation (CV) of dry matter (DMI), organic matter (OMI), neutral detergent fiber (NDFI), crude protein (CPI) and total digestible nutrients (TDNI) intakes, according to the levels of replacement of corn by forage cactus meal

\begin{tabular}{|c|c|c|c|c|c|c|c|}
\hline \multirow[t]{2}{*}{$\begin{array}{l}\text { Itens } \\
\text { Items }\end{array}$} & \multicolumn{4}{|c|}{$\begin{array}{l}\text { Níveis de substituição(\%) } \\
\text { Levels of replacement (\%) }\end{array}$} & \multirow[t]{2}{*}{$\begin{array}{l}\mathrm{ER} \\
R E\end{array}$} & \multirow[t]{2}{*}{$\mathrm{r}^{2}$} & \multirow[t]{2}{*}{$\mathrm{CV}(\%)$} \\
\hline & 0 & 33 & 66 & 100 & & & \\
\hline CMS (kg/dia) $(D M I-k g / d a y)$ & 0,63 & 0,66 & 0,66 & 0,64 & $Y=0,65$ & - & 6,05 \\
\hline $\mathrm{CMS}(\% \mathrm{PV})(\% L W)$ & 3,11 & 3,47 & 3,22 & 3,31 & $\mathrm{Y}=3,28$ & - & 7,00 \\
\hline $\mathrm{CMS}(\mathrm{g} / \mathrm{kg} 0,75)(D M I-\mathrm{g} / \mathrm{kg} 0,75)$ & 66,3 & 72,5 & 68,4 & 71,9 & $Y=69,77$ & - & 4,38 \\
\hline CMO (kg/dia) (OMI - kg/day) & 0,60 & 0,61 & 0,61 & 0,59 & $\mathrm{Y}=0,60$ & - & 4,75 \\
\hline CFDN (kg/dia) $(N D F I-k g / d a y)$ & 0,32 & 0,32 & 0,34 & 0,33 & $Y=0,33$ & - & 6,24 \\
\hline CPB $(\mathrm{kg} / \mathrm{dia})(C P I-\mathrm{kg} / d a y)$ & 0,12 & 0,13 & 0,12 & 0,13 & $Y=0,125$ & - & 4,14 \\
\hline CNDT (kg/dia) $(T D N I-k g / d a y)$ & 0,40 & 0,39 & 0,37 & 0,34 & $\mathrm{Y}=0,409-0,0006^{*} \mathrm{FP}$ & 0,88 & 7,49 \\
\hline
\end{tabular}

* Significativo $(P<0,05)$ pelo teste $t$ (Significant $[P<.05]$ by $t$ test $)$.

FP Nível de subsituição (Level of replacement).

Tabela 5 - Média, equação de regressão ajustada (ER), coeficiente de determinação ( $\mathrm{r}^{2}$ ) e variação (CV) para os coeficientes de digestibilidade aparente de matéria seca (CDMS), matéria orgânica (CDMO), fibra em detergente neutro (CDFDN), proteína bruta (CDPB) e percentagem de NDT, em função dos níveis de substituição do milho pelo farelo de palma

Table 5 - Mean, fitted regression equation (RE), coefficients of determination $\left(r^{2}\right)$ and variation (CV) for the apparent digestibility coefficients of dry matter (DCDM), organic matter (DCOM), neutral detergent fiber (DCNDF), crude protein (DCCP) and TDN values, according to the levels of replacement of corn by forage cactus meal

\begin{tabular}{|c|c|c|c|c|c|c|c|}
\hline \multirow[t]{2}{*}{$\begin{array}{l}\text { Itens } \\
\text { Items }\end{array}$} & \multicolumn{4}{|c|}{$\begin{array}{c}\text { Níveis de substituição (\%) } \\
\text { Levels of replacement (\%) }\end{array}$} & \multirow[t]{2}{*}{$\begin{array}{l}\mathrm{ER} \\
R E\end{array}$} & \multirow[t]{2}{*}{$\mathrm{r}^{2}$} & \multirow[t]{2}{*}{$\mathrm{CV}(\%)$} \\
\hline & 0 & 33 & 66 & 100 & & & \\
\hline CDMS (DCDM) & 65,9 & 64,8 & 60,1 & 58,7 & $\mathrm{Y}=66,329-0,0787 \mathrm{FP}$ & 0,93 & 4,98 \\
\hline $\mathrm{CDMO}(D C O M)$ & 67,5 & 66,5 & 62,0 & 60,4 & $\mathrm{Y}=67,99-0,0779 \mathrm{FP}$ & 0,94 & 4,99 \\
\hline CDFDN $(D C N D F)$ & 55,5 & 51,9 & 45,8 & 48,5 & $Y=50,43$ & - & 8,28 \\
\hline $\operatorname{CDPB}(D C C P)$ & 74,2 & 75,5 & 75,2 & 73,9 & $\mathrm{Y}=74,7$ & - & 3,65 \\
\hline $\operatorname{NDT}(T D N)$ & 62,9 & 60,5 & 54,8 & 51,4 & $\mathrm{Y}=63,4043-0,121 \mathrm{FP}$ & 0,98 & 5,01 \\
\hline
\end{tabular}

* Significativo $(P<0,05)$ pelo teste $t$ (Significant $[P<.05]$ by $t$ test $)$.

FP Nível de subsituição (Level of replacement).

CDFDN. Esse fato pode ser explicado pelo tipo de carboidrato na palma forrageira, em especial, hemicelulose, graças à sua resistência parcial na fermentação ruminal - fator limitante $d$ taxa degradação dos carboidratos da parede celular no rúmen (Fahey \& Berger, 1988).

Na Tabela 6, encontram-se os valores médios dos coeficientes de digestibilidade aparente estimados por meio da coleta total de fezes (CTF) e dos indicadores fibra em detergente neutro indigestível (FDNi) e fibra em detergente ácido indigestível (FDAi).

Não houve diferença para os coeficientes de digestibilidade pela CTF e FDNi e entre FDAi e FDNi. Entretanto, ao se comparar FDAi e CTF, detectou-se diferença $(\mathrm{P}<0,05)$, em que o uso do

R. Bras. Zootec., v.34, n.1, p.351-356, 2005 indicador interno FDAi na avaliação da digestibilidade dos nutrientes subestima os valores encontrados, em comparação ao CTF. Estes resultados diferem dos encontrados por Alves et al. (2003), determinados em ovinos, e Berchielli et al. (2000), em bovinos, que não verificaram diferença entre CTF e FDAi, para os mesmos nutrientes avaliados. Entretanto, estão de acordo com Zeoula et al. (2001) que não observaram diferenças entre FDNi e CTF para a estimativa da digestibilidade de MS em ovinos.

\section{Conclusões}

O farelo de palma forrageira não substitui o milho moído como fonte de energia para ovinos em cresci- 
Tabela 6 - Coeficiente de digestibilidade aparente da MS (CDMS), PB (CDPB) e FDN (CDFDN), de acordo com a coleta total de fezes (CTF), fibra em detergente neutro indigestível (FDNi) ou fibra em detergente ácido indigestível (FDAi)

Table 6 - Apparent digestibility coefficient of DM (DCDM), $C P(D C C P)$ and NDF (DCNDF), according to the total feces collection (TFC), indigestible neutral detergent fiber (NDFi) or indigestible acid detergent fiber (ADFi)

\begin{tabular}{lcccc}
\hline & \multicolumn{3}{c}{ Métodos (Methods) } & CV (\%) \\
\cline { 2 - 4 } & CTF & FDNi & FDAi & \\
& $T F C$ & $N D F i$ & $A D F i$ & \\
\hline CDMS $(D M)$ & $62,41 \mathrm{a}$ & $60,97 \mathrm{ab}$ & $59,78 \mathrm{~b}$ & 3,81 \\
CDMO $(O M)$ & $64,11 \mathrm{a}$ & $62,73 \mathrm{ab}$ & $61,60 \mathrm{~b}$ & 3,54 \\
CDPB $(C P)$ & $74,69 \mathrm{a}$ & $73,75 \mathrm{ab}$ & $72,98 \mathrm{~b}$ & 2,11 \\
CDFDN $(N D F)$ & $50,41 \mathrm{a}$ & $48,34 \mathrm{ab}$ & $46,92 \mathrm{~b}$ & 6,33 \\
\hline
\end{tabular}

Médias, na linha, seguidas de mesma letra não diferem pelo teste Tukey $(P>0,05)$.

Means in the line, followed by the same letter, do not differ by Tukey test $(P>$.05).

mento. O coeficiente de digestibilidade dos nutrientes avaliados não apresentou resultado satisfatório com o aumento dos níveis de farelo de palma forrageira em substituição do milho.

A avaliação da digestibilidade pelo método FDNi foi eficiente em determinar a digestibilidade, em comparação ao método de coleta total.

\section{Literatura Citada}

ALVES, K.S.; CARVALHO, F.F.R.; FERREIRA, M.A. et al. Níveis de energia em dietas para ovinos Santa Inês: digestibilidade aparente. Revista Brasileira de Zootecnia, v.32, n.6, p.1962-1968, 2003 (Supl. 2).

BERCHIELLI, T.T.; ANDRADE, P.; FURLAN, C.L. Avaliação de indicadores internos em ensaio de digestibilidade. Revista Brasileira de Zootecnia, v.29, n.3, p.830-833, 2000.

BRANCO, A.F.; MOURO, G.F.; MACEDO, F.A.F. et al. Substituição do milho pela farinha de mandioca de varredura em dietas de cabras em lactação: Digestibilidade dos nutrientes e nutrientes digestíveis totais. In: REUNIÃO ANUAL DA SOCIEDADE BRASILEIRA DE ZOOTECNIA, 38., 2001, Piracicaba. Anais... Piracicaba: Sociedade Brasileira de Zootecnia, p.996-1000. 2001.

COELHO DA SILVA, J.F.; LEÃO, M.I. Fundamentos de nutrição dos ruminantes. Piracicaba: Livroceres, 380p. 1979.

FAHEY, G.C.; BERGER, L.L. Los carbohidratos en la nutricion de los rumiantes. In: CHURCH, D.C. (Ed) The ruminant animal: digestive physiology and nutrition. Zaragoza: Acribicia, 1988. p.305-338.

GARCIA, C.A.; SILVA SOBRINHO, A.G. Desempenho e características das carcaças de ovinos alimentados com resíduo de panificação "biscoito". In: REUNIÃO ANUAL DA SOCIEDADE BRASILEIRA DE ZOOTECNIA, 35., 1998, Botucatu. Anais... Botucatu: Sociedade Brasileira de Zootecnia, 1998. p.29-31.

GERON, L.J.V.; ZEOULA, L.M.; CALDAS NETO, S.F. et al. Substituição do milho pela farinha de varredura Manihot esculenta Crantz em rações para ovinos. 1. Ingestão de matéria seca e valor energético. In: REUNIÃO ANUAL DA SOCIEDADE BRASILEIRA DE ZOOTECNIA, 38., 2001, Piracicaba. Anais... Piracicaba: Sociedade Brasileira de Zootecnia, 2001. p.1219-1220.

MENEZES, M.P.C.; RIBEIRO, M.N.; COSTA, R.G.; et al. Substituição do milho pela casca de mandioca (Manlhot esculenta Crantz) em rações completas para caprinos: digestibilidade dos nutrientes. In: REUNIÃO ANUAL DA SOCIEDADE BRASILEIRA DE ZOOTECNIA, 39., 2002, Recife. Anais... Recife: Sociedade Brasileira de Zootecnia, 2002. CD-ROM

MOURO, G.F.; BRANCO, A.F.; MACEDO, F.A.F.; et al. Susbstituição do milho pela farinha de mandioca de varredura em dietas de cabras em lactação: produção e composição do leite e digestibilidade aparente da matéria seca, matéria orgânica e amido. In: REUNIÃO ANUAL DA SOCIEDADE BRASILEIRA DEZOOTECNIA, 38., 2001, Piracicaba. Anais... Piracicaba: Sociedade Brasileira de Zootecnia, 2001. p.993-995.

NATIONAL RESEARCH COUNCIL - NRC. Nutrient requirement of sheep. 6 ed. Washington, D.C.: National Academy Press, 1985. 99p.

SILVA, M.F.; BATISTA, A.MV.; ALMEIDA, O.C. Efeito da adição de capim elefante a dietas à base de palma forrageira sobre a fermentação ruminal em bovinos. In: REUNIÃO ANUAL DA SOCIEDADE BRASILEIRA DE ZOOTECNIA, 34., 1997, Juiz de Fora. Anais... Juiz de Fora: Sociedade Brasileira de Zootecnia, 1997. p.140-142.

SILVA, D.J. Análise de alimentos (métodos químicos e biológicos). 2.ed. Viçosa, MG: Universidade Federal de Viçosa, 1990. 166p.

SNIFFEN, C.J.; O`CONNOR, J.D.; Van SOEST, P.J. et al. A net carbohydrate and protein system for evaluating cattle diets: II. Carbohydrate and protein availability. Journal of Animal Science, v.70, n.11, p.3562-3577, 1992.

UNIVERSIDADE FEDERAL DE VIÇOSA - UFV. SAEG Sistemas de Análises Estatísticas e Genéticas. Versão 7.1. Viçosa, MG, 1997. 150p. (manual do usuário).

Van SOEST, P.J.; ROBERTSON, J.B.; LEWIS, B.A. Methods for extraction fiber, neutral detergent fiber and nonstarch polysaccarides in relation to animal nutrition. Journal of Dairy Science, v.83, n.1, p.3583-3597, 1991.

VÉRAS, R.M.L.; FERREIRA, M.A.; CARVALHO, F.F.R. et al. Farelo de palma forrageira (Opuntia fícus indica Mill) em substituição ao milho.1. Digestibilidade aparente dos nutrientes. Revista Brasileira de Zootecnia, v.31, n.3, p.1302-1306, 2002.

WANDERLEY, W.L.; FERREIRA, M.A.; ANDRADE, D.K.B.; et al. Palma forrageira (Opuntia ficus indica Mill) em substituição a silagem de sorgo (Sorghum Bicolor (L.) Moench) na alimentação de vacas leiteiras. Revista Brasileira de Zootecnia, v.31, n.1, p.273-281, 2002

ZEOULA, L.M.; DIAN, P.H.; CALDAS NETO, S.F. et al. Avaliação de indicadores internos em ensaios de digestibilidade para ruminantes. In: REUNIÃO ANUAL DA SOCIEDADE BRASILEIRA DE ZOOTECNIA, 38., 2001, Piracicaba. Anais... Piracicaba: Sociedade Brasileira de Zootecnia, 2001a. p.1122-1124.

R. Bras. Zootec., v.34, n.1, p.351-356, 2005

Recebido em: $14 / 08 / 03$

Aceito em: 29/09/04 